\title{
As políticas de educação continuada por competências: um estudo das configurações subjetivas do trabalhador público brasileiro
}

\author{
Luana Silvy de Lorenzi Tezza Magnin ${ }^{1}$ \\ Miriam Aparecida Graciano de Souza Pan ${ }^{2}$ \\ Universidade Federal do Paraná (Curitiba, PR, Brasil)
}

Ser competente tornou-se objeto de consumo dos trabalhadores, que se dedicam ilimitadamente ao seu desenvolvimento. Este artigo analisa os modos de produção subjetiva do trabalhador público brasileiro a partir das amplas políticas de capacitação por competências, essas pouco problematizadas em seus fundamentos. Trata-se de um estudo documental discursivo e teórico-conceitual, realizado via perspectiva bakhtiniana, em que se analisou a política nacional de desenvolvimento de pessoal, o relatório da Comissão Internacional sobre a Educação para a UNESCO e o Programa de Capacitação da ENAP. O enunciado das competências, como forma de oportunizar rápida qualificação e inclusão, está comprometido com uma visão de educação liberal e flexível que transfere ao servidor a responsabilidade pela (in)eficiência da gestão pública brasileira. Conclui-se que embora os fundamentos do termo "competências" estejam silenciados na literatura, seus usos e efeitos podem ser lidos em sua perspectiva pragmática, produzindo um trabalhador autônomo, flexível e que se responsabiliza individualmente por suas competências e capacidade de entrega. $\mathrm{Na}$ promessa de rápida qualificação e inclusão, o discurso de competência funciona como potente e competente aliado do Estado capitalista.

Palavras-chave: Capacitação pública, Competências, Bakhtin, Educação continuada, Discurso, Subjetividade.

Competency-based continuing education policies: a study on Brazilian public worker's subjectivity

Being competent has become workers' desire to self-improve, dedicating themselves to develop at all times and places. This study analyses the modes of subjective production of the Brazilian public worker based on broad competency-based training policies, which haven't been enough problematized. This research follows a contextual discourse and theoretical documentation adopting Bakhtin's perspective, researching Brazilian public policy on workers' education, as well as the Report of the International Commission on Education for UNESCO and the Brazilian program on professional qualification (ENAP). Results show that competencies discourse is tied to a vision of liberal and flexible education that transfers to the public worker the responsibility of Brazilian public management's (in)efficiency. Although the fundamentals of the term "competencies" rarely appear in related literature, its usages and effects appear in its pragmatically perspective, producing a public worker who believes that he is individually responsible for its competencies and its deliverability. As it promises quick qualification and inclusion, competency discourse is a potent and competent allied of the capitalist state.

Keywords: Public training, Competencies, Bakhtin, Continuing education, Discourse, Subjectivity.

\section{Introdução}

\begin{abstract}
A teoria das competências tem estado em grande evidência nas políticas e práticas de educação continuada da administração pública brasileira, perpassando as áreas de saúde, educação e trabalho. Com vistas a melhorar a qualidade dos serviços ofertados ao cidadão, o governo passa a investir na sistematização das práticas de capacitação dos servidores públicos, oportunizada por meio do desenvolvimento continuado de suas competências (Decreto n⿳0 5.707, de 23 de fevereiro de 2006).
\end{abstract}

1 Analista em gestão pública da Fundação Oswaldo Cruz (Fiocruz/PR). Doutoranda em Administração e Mestre em Psicologia pela Universidade Federal do Paraná (UFPR). Pesquisa realizada com bolsa Capes.

2 Departamento de Psicologia da Universidade do Paraná (UFPR). PhD em Educação Superior pela University of Texas at Austin e doutora em Letras pela UFPR. 
A precarização das condições de trabalho e a insatisfação com a qualidade dos serviços públicos brasileiros foram discutidas por diversos estudos (Andrade, 2011; Chiavegato Filho, \& Navarro, 2012; Costa, 2005). Com foco na melhoria de resultados, surge o Decreto 5.707/2006, que regulamenta os planos de capacitação de servidores e determina às entidades públicas o planejamento e a execução de um plano de capacitação orientado por competências.

As finalidades da instituição de uma política nacional de desenvolvimento de pessoal relacionam-se diretamente com a necessidade de profissionalização do serviço público, o que envolve a melhoria da qualidade dos serviços prestados ao cidadão, a transparência e a divulgação das ações de capacitação promovidas, a racionalização e efetividade dos gastos com capacitação e o planejamento e alinhamento entre as capacitações ofertadas e os objetivos das instituições (Decreto 5.707/2006).

O conceito de competência foi inicialmente proposto em 1973, por David McClelland, psicólogo motivacional estadunidense, que buscava um método de seleção de pessoas alternativo aos testes psicológicos. A partir da segunda metade do século XX, diversos autores retomaram e remodelaram o conceito, de modo que atualmente é possível citar múltiplas definições de competência (Boterf, 1997; Fleury, \& Fleury, 2001; Perrenoud, 1998; Zarifian, 2001, entre outros). Segundo Dutra, Fleury e Ruas (2012), as últimas revisões do conceito estão associadas à agregação de valor e entrega a partir de características pessoais.

A teoria tornou-se discurso dominante nas práticas de capacitação pública, sem que suas condições de produção e seus efeitos sobre o trabalhador fossem suficientemente problematizados. Tornar-se competente passou a compor o projeto de vida de muitos trabalhadores brasileiros assim como a oportunidade de concorrer no acirrado mercado de trabalho mundial. Compreender a teoria das competências, sua ascensão enquanto discurso oficial das políticas de capacitação no Brasil e seus efeitos na configuração subjetiva do trabalhador são objetos de investigação deste estudo.

\section{O que as políticas públicas de educação preconizam e produzem?}

Uma política pública materializa e concretiza o poder do Estado em determinar as diretrizes que norteiam ações dos diferentes entes públicos. As políticas públicas podem ser definidas como um conjunto de ações articuladas, com capacidade de impacto, que compreendem uma dimensão ético-política e que implicam formas de relação do Estado com a sociedade (Sposito, 2008). Segundo Machado e Pan (2014, p. 185), fundamentados na teoria do discurso do Círculo de Bakhtin ${ }^{3}$, "as políticas podem ser entendidas enquanto práticas discursivas, uma vez que se concretizam enquanto enunciados de sujeitos (individuais ou coletivos) posicionados nas relações sociais de poder".

Quando as políticas públicas incidem sobre a educação, atuam também sobre os modos de subjetivação de uma sociedade, já que se configuram como orientadoras dos processos educacionais (Machado, \& Pan, 2012). Portanto, a legislação que orienta as práticas educativas dos servidores não é neutra nem arbitrária, como se fosse comprometida apenas com objetivos definidos e explícitos (como a melhoria da qualidade dos serviços ofertados), mas reflete e refrata o posicionamento ideológico de seus idealizadores, e é produtora de modos específicos e determinados de ser e existir enquanto trabalhador público. Analisar uma política pública requer, portanto, uma concepção teórica sobre a elaboração e a leitura de um texto.

3 Círculo de Bakhtin compreende um grupo multidisciplinar de intelectuais russos que se reuniam regularmente entre 1919 e 1929 para debater ideias. Desses, Bakhtin, Voloshinov e Medvedev merecem destaque pela representatividade de seu pensamento e pela confusão em relação à autoria dos textos produzidos (Faraco, 2003). 
A teoria enunciativa do Círculo de Bakhtin possibilita a leitura de uma política como a manifestação de relações de poder, produtora de modos de subjetivação. $\mathrm{O}$ enunciado, por sua vez, se caracteriza por estar sempre posto em resposta a enunciados anteriores, e em antecipação a enunciados futuros. Está, portanto, situado historicamente e, ao mesmo tempo, no contexto de um grupo social, nas relações de tensão que o constituem - relações dialógicas - e que compõem a arena de vozes sociais, ou seja, as diferentes posições verbo-axiológicas nas quais um sujeito individual enuncia. É ato (que não repete, sui generis), pois implica em um posicionamento ético de um sujeito singular e único, historicamente localizado, produtor de sentidos (Faraco, 2003).

Desse modo, no planejamento de práticas formativas e na elaboração de planos de capacitação, considera-se o público-alvo como aquele que se pretende informar e formar, na medida em que se busca configurar um modo específico de subjetividade (Amorim, 2002; Machado, \& Pan, 2012). Os modos de subjetivação prescritos no texto de uma política pública atuam na forma como o servidor público dá significado à sua existência - como age, posiciona-se, manifesta-se e/ou se silencia - o que demanda uma análise aprofundada dos documentos oficiais relacionados à capacitação por competências e das práticas formativas decorrentes.

O enunciado das competências tornou-se tão potente no atual cenário público brasileiro, abrangendo as áreas de saúde, educação e trabalho da administração pública direta (União, Estados federados, Distrito Federal, municípios e seus respectivos órgãos) e indireta (autarquias, fundações empresas públicas, sociedades de economia mista), que nos leva a indagar sobre o porquê de sua ascensão e do seu rápido poder de propagação. Para perfilar a questão, interessa-nos perscrutar o modo de produção subjetiva configurada por esse enunciado, qual seja: que tipo de trabalhador as práticas de educação pautadas em competências produzem, nas mais diversas áreas de atuação pública? Desse modo, este artigo objetiva analisar os modos de configuração subjetiva presentes nas atuais políticas norteadoras das práticas de educação do trabalhador público brasileiro, a partir do enunciado das competências.

\section{Método: estratégias de leitura e pesquisa}

Trata-se de um estudo documental realizado por meio de dois procedimentos metodológicos: um teórico-conceitual, referente ao conceito das competências, e o outro, uma análise discursiva das políticas públicas de educação.

Considerando a dominância da teoria das competências nas políticas educativas, o estudo teórico-conceitual buscou a identificação de artigos cujos autores apresentassem análise crítica aos seus pressupostos. Para tanto, foi pesquisada a base Educational Technology Abstracts, por meio dos descritores "competence", "competency" e "work", sem limite de data. Por meio da leitura dos títulos e resumos, foram identificados e selecionados artigos que contribuíssem para a problematização da teoria, constituindo-se assim a arena discursiva; ou seja, sua aparição e ascensão no cenário mundial, sua localização espaço-temporal e sua dimensão dialógica: as tensões a que responde e as respostas que convoca, em busca de consenso e dominação.

A análise discursiva das políticas públicas de educação englobou os seguintes documentos públicos: 1) o relatório "Educação: um tesouro a descobrir", da Comissão Internacional sobre a Educação para o século XXI, de 2003, para a United Nations Educational Scientific and Cultural Organization (UNESCO); 2) o Decreto 5.707/2006, que regulamenta a capacitação dos servidores públicos; e 3) o programa de gestão de pessoas do catálogo de cursos de 2013 da Escola Nacional de Administração Pública (ENAP). Esses documentos foram acessados pelos respectivos sítios oficiais do governo federal e da UNESCO ${ }^{4}$.

4 Sítios oficiais: Relatório da Comissão Internacional sobre a Educação para o século XXI: http://www.unesco.org/; Decreto 5.707/2006: http://www.planalto.gov.br/; Programa de gestão de pessoas do catálogo de cursos de 2013 da ENAP: http://www.enap.gov.br/. 
Os três documentos foram analisados na qualidade de enunciados, conforme definido anteriormente pela concepção bakhtiniana de discurso, e relacionados à pesquisa teóricoconceitual sobre o enunciado das competências. A relação se estabeleceu na identificação da concepção de trabalhador preconizada pela teoria das competências e na forma como essa concepção está desenhada na política pública, ou seja, como o trabalhador está significado nas políticas públicas de educação.

Os documentos, todos de domínio público, foram selecionados por representarem marcos históricos: o Relatório para a UNESCO (Delors, 2003) fortalece, internacionalmente, a concepção da educação continuada na contemporaneidade; o Decreto 5.707/2006 regulamenta a capacitação do servidor; e o Programa de Gestão de Pessoas do Catálogo de Cursos da ENAP (2013) institui práticas formativas no âmbito do serviço público brasileiro.

Os textos foram lidos integralmente com o foco na compreensão global e seleção de trechos significativos, entendidos como aqueles que produzem a configuração do sentido do servidor público que é objeto da capacitação por competências. Deu-se ênfase especial às partes previamente selecionadas de cada documento que faziam referência direta à teoria das competências e à capacitação do servidor público, com vistas a analisar quais os sentidos construídos sobre o trabalhador público e quais efeitos têm sido produzidos a partir das políticas educativas pautadas no enunciado das competências.

Em um estudo documental é preciso explicitar a concepção que se tem de um documento. Segundo Flick (2009), os documentos são produzidos por pessoas que visam atingir algum objetivo, para alguém. Dessa forma, os documentos analisados foram situados em relação às suas condições de produção e seus efeitos de sentido. Ou seja, foram lidos a partir da identificação das premissas e dos pressupostos adotados pelas equipes responsáveis pela elaboração e redação dos documentos e considerados enquanto posicionamentos ideológicos que têm força de verdade no contexto histórico e político atual. Foram lidos na qualidade de textos vivos, textos "presentativos" (no sentido de estarem presentes) e significativos (Spink, 1999, p. 124).

A teoria das competências, assim, foi estudada em sua dimensão de ato designativo de políticas públicas, cujos efeitos sobre práticas educativas produzem sentidos sobre seus próprios beneficiários, definindo, além de uma técnica de capacitação, uma tecnologia de produção de sentidos sobre o trabalhador.

Os resultados são apresentados segundo sua cronologia e geografia (cronotopia): primeiramente, a teoria das competências é situada nos cenários teórico e científico, com ênfase para a proposição inicial realizada por McClelland, nos Estados Unidos. Ainda no campo internacional, é apresentada a concepção de educação continuada e os pressupostos presentes no relatório sobre a educação para o século XXI. Em seguida, é analisada a ascensão da teoria das competências enquanto enunciado dominante nas políticas públicas brasileiras de capacitação. Ao final, é realizada a discussão, fundamentada em autores que tecem crítica à teoria das competências que está legitimada nas políticas.

\section{As competências como proposta democrática e inclusiva: a década de 1970}

O conceito de competência foi inicialmente proposto em 1973 pelo psicólogo David McClelland, conhecido por sua teoria das necessidades adquiridas. No âmbito da educação, a década de 1970 foi marcada por grandes reformas das democracias liberais, que buscaram promover os direitos humanos, a igualdade de oportunidades e a educação para todos, avançando na inclusão e suas artimanhas (Sawaia, 2001). A década foi também marcada pela crise do sistema de produção capitalista. Na época, McClelland era professor da Universidade de Harvard e trabalhava para o governo estadunidense; buscava uma ferramenta mais efetiva que os testes de 
inteligência para selecionar pessoas para o Departamento de Estado, e abrandar os graves efeitos da crise para o país.

Nesse artigo, é grande a preocupação de McClelland em relação aos usos dos testes de inteligência, que tendem a classificar os indivíduos em dois grandes polos: os "inteligentes e aptos", e "burros e inaptos". Para além da crítica desse grande dualismo semântico, o autor apontava um interesse eminentemente antidiscriminatório e uma grande preocupação social. Segundo ele, quando uma cultura é mais valorizada que a outra, as pessoas que fazem parte das minorias são discriminadas não apenas pelo meio social, como também por meio dos testes, os quais muitas vezes não mediam o que se propunham a verificar, impedindo pessoas de serem admitidas em universidades ou no mercado de trabalho.

O autor avança ao apresentar uma teorização poderosa para responder às necessidades de reestruturação do processo produtivo daquele período e superar os problemas sociais existentes, alinhando-se ao discurso da igualdade de oportunidades muito difundido nos Estados Unidos nesse delicado momento de guerra fria, no qual o exército vermelho da União Soviética se torna o mais poderoso e influente do mundo. McClelland apresenta uma solução pragmática para atender à crise e às exigências dos direitos civis, oferecendo um modelo teórico promissor para o desenvolvimento de competências individuais, a ser alavancado pela educação, da discriminação e exclusão à oportunidade de inclusão a todos, conjugando à educação por competências a promessa de tornarem-se parte do sistema produtivo, com maior poder de consumo, maior autonomia e mobilidade social.

O enunciado das competências atingiu diversas correntes de pensamento, como a behaviorista, a funcionalista e a construtivista, pois respondeu diretamente às demandas pragmáticas do capitalismo - educação rápida e flexível, autônoma e utilitária -, o que contribuiu para sua forte propagação (Palangana, 2002; Jeris, Johnson, Isopahkala, Winterton, \& Anthony, 2005; Ramos, 2011, Silva, 1998).

Assim, em um momento histórico de crise estrutural do capital (Pereira, 2006) e em resposta aos interesses de reestruturação do processo produtivo, várias teorias e políticas associaram, a partir das publicações de McClelland, nos Estados Unidos, a capacitação por competências à oportunidade de inclusão, tornando o discurso dominante nas práticas e nos programas de capacitação. Assim, por meio do enunciado das competências, a educação é lançada - numa perspectiva salvacionista - como a grande saída para a sociedade marcada pela exclusão. É o que acontece no relatório "Educação: um tesouro a descobrir", que será analisado a seguir.

\section{O discurso da educação para todos: relatório da Comissão Internacional sobre a Educação}

A concepção de educação ao longo da vida foi muito difundida a partir da publicação do relatório "Educação: um tesouro a descobrir", da Comissão Internacional sobre a Educação para o século XXI, trabalho esse coordenado por Jacques Delors (2003). Nesse relatório, institui-se o discurso de educação para todos, como forma de inclusão aos que não puderam concluir seus estudos. Essa educação inclusiva e geradora de novas oportunidades seria realizada por meio da flexibilização da educação.

Os resultados do estudo apontam sentidos que configuram o trabalhador a partir de termos de forte apelo e tradição, como "princípio da igualdade de oportunidades", "exigência democrática" e "justiça”. Identificamos abaixo trechos significativos do relatório que funcionam como marcadores de sentidos e que perpassam o texto todo: 
- A educação ao longo da vida promoveria a igualdade de oportunidades: "o princípio da igualdade de oportunidades constitui um critério essencial para todos os que se dedicam à progressiva concretização das diferentes vertentes da educação ao longo de toda a vida". (Delors, 2003, p. 106);

- Embora fatores políticos, econômicos e sociais sejam reconhecidos, acredita-se que a adoção de modelos flexíveis de educação promoveriam a igualdade de oportunidades, atendendo à exigência democrática e à concepção de justiça: "Correspondendo a uma exigência democrática, seria justo que este princípio (igualdade de oportunidades) estivesse presente, de maneira formal, em modalidades mais flexíveis de educação" (Delors, 2003, p. 106); "A Comissão pensa que sistemas mais flexíveis... constituem respostas válidas às questões postas pela inadequação entre a oferta e a procura de emprego" (Delors, 2003, p. 17).

- Os desvios no percurso educativo poderiam ser corrigidos pela educação ao longo da vida; o compromisso pessoal e certo apoio social seriam suficientes para revertê-los: "a sociedade apareceria... como responsável pelas igualdades e possibilidades de escolarização e de formação posterior oferecidas a cada um no decurso da sua vida, sejam quais forem os desvios ou incertezas no seu percurso educativo". (Delors, 2003, p. 106); "Se juntarmos a estas novas exigências a busca de um compromisso pessoal do trabalhador, considerado como agente de mudança..." (Delors, 2003, p. 94).

- A educação é responsável pela transmissão de saberes evolutivos e o desenvolvimento de competências: "A educação deve transmitir, de fato, de forma maciça e eficaz, cada vez mais saberes e saber-fazer evolutivos, adaptados à civilização cognitiva, pois são as bases das competências do futuro" (Delors, 2003, p. 89).

- As competências devem ser desenvolvidas no âmbito individual; o trabalhador, ao desenvolver competências, por meio da educação continuada, oportuniza sua própria empregabilidade: "a competência... se apresenta como uma espécie de coquetel individual, combinando a qualificação, em sentido estrito, adquirida pela formação técnica e profissional, o comportamento social, a aptidão para o trabalho em equipe, a capacidade de iniciativa, o gosto pelo risco" (Delors, 2003, p. 94).

- A educação deve estar alinhada às exigências do mercado de trabalho: "Relacionar a educação com o mundo do trabalho é outra das tarefas urgentes". (Delors, 2003, p. 238)

- A educação ao longo da vida, por meio do desenvolvimento de competências, traz ganhos para o trabalhador: "[a educação ao longo da vida] junta o conhecimento não-formal ao conhecimento formal, o desenvolvimento de aptidões inatas à aquisição de novas competências. Implica esforço, mas traz também a alegria da descoberta". (Delors, 2003, p. 107).

No relatório, difunde-se a ideia de que o desenvolvimento das competências ao longo da vida promoveria a igualdade de oportunidades necessária à inclusão dos indivíduos desfavorecidos, produzindo sentidos que assumem o caráter de verdade quase universal. De fato, a flexibilização da educação e sua aproximação com o trabalho é frequentemente apontada como a grande saída para a eliminação dos problemas sociais. Segundo Rodrigues (2008), o discurso da educação continuada está alinhado a dois outros: por um lado, fortalece o discurso do mercado; por outro, nutre a ilusão do trabalhador de ser incluído na chamada sociedade do conhecimento, mediante seu esforço individual em recorrer a espaços formativos dos mais diversos. Silva (1998) aponta que esse discurso, ao desvalorizar os saberes produzidos na escola, torna secundários os investimentos do Estado na educação formal.

Ler e compreender um relatório desse porte, a partir da teoria de leitura de Bakhtin (2011), requer identificar sua criação e destinação, ou seja, foi emitido por uma comissão internacional de educação; não é apenas uma voz dentre outras, mas é um enunciado potente que carrega uma concepção política e prática de educação, instaurando práticas sociais, como as que serão abordadas a seguir. 


\section{A instituição da política nacional de desenvolvimento de pessoal no Brasil: anos 2000}

A política nacional de desenvolvimento de pessoal no Brasil é instituída pelo Decreto 5.707/2006, e se ampara na concepção de educação continuada difundida mundialmente pelo relatório da Comissão Internacional sobre a Educação, educação essa alinhada ao desenvolvimento individual de competências.

O Decreto relaciona as ações de capacitação aos objetivos das instituições, tendo como referência o plano plurianual. Com isso, busca-se dar continuidade às ações implementadas, de modo que elas não variem conforme os objetivos ou prioridades pessoais daqueles que venham a ocupar postos de liderança nas organizações, mas se articulem de acordo com o plano de médio prazo estabelecido.

Ao articular o plano de capacitação ao plano plurianual, o governo em vigor reconhece o planejamento da educação continuada como indispensável para que uma instituição pública atinja seus objetivos; ou seja, a educação do servidor deixa de ocupar uma função acessória, e passa a se constituir em função estratégica para a instituição - e para o governo.

O Decreto 5.707/2006 apresenta ao servidor a oportunidade de qualificação de modo continuado por meio do desenvolvimento de suas competências, o que é inédito no âmbito público brasileiro. Porém, o Decreto e os planos de capacitação das instituições públicas pouco especificam sobre a teoria das competências e que tipo de trabalhador visam formar, apenas relacionam diretamente e de modo natural a "adequação das competências requeridas dos servidores aos objetivos das instituições”, conforme Artigo 1ํ do Decreto 5.707/2006.

$\mathrm{Na}$ área da administração não há consenso entre os empregos do termo competência e verifica-se uma diversidade absoluta entre seus usos e empregos (Faria, \& Leal, 2007), embora sua utilização - e seus efeitos de sentido - transmitam uma ideia de grande coerência metodológica para a produção de resultados e a adequação do trabalhador ao sistema produtivo. Também na legislação pública brasileira, a teoria das competências é adotada sem nenhum tipo de referência, desvinculada de sua arena enunciativa, de seu dialogismo, de sua historicidade e de seu posicionamento ideológico; a competência é um conceito que "pertence à categoria das palavras vagas" (Van der Klink, \& Boon, 2002, p. 79).

\section{A ENAP como difusora das políticas públicas de educação: catálogo 2013}

Alinhada ao Decreto 5.707/2006 e à concepção de educação flexível difundida pelo relatório da Comissão Internacional sobre a Educação apresentados, a ENAP, fundação pública vinculada ao Ministério do Planejamento, Orçamento e Gestão, criada em 1986 e situada em Brasília, tem utilizado e incentivado o uso da abordagem por competências em seus cursos de capacitação direcionados aos servidores públicos, realizados nas principais capitais brasileiras e muitas vezes em parceria com escolas de governo estaduais.

A ENAP tem como objetivo promover, elaborar e executar os programas de capacitação de recursos humanos para a Administração Pública Federal, visando o desenvolvimento e a aplicação de tecnologias de gestão que aumentem a eficácia, a qualidade e a produtividade permanente dos serviços prestados pelo Estado aos cidadãos ${ }^{5}$.

O programa de Capacitação em Gestão de Pessoas da ENAP foi utilizado nessa pesquisa como um importante material de investigação sobre como a política de capacitação é aplicada,

5 Conforme sítio da ENAP: www.enap.gov.br 
por meio de cursos de capacitação ofertados aos servidores. Uma das trilhas de formação ofertadas pela ENAP no Catálogo de cursos 2013 refere-se ao programa de Gestão de Pessoas. Eis o públicoalvo desse programa: "servidores públicos federais que exerçam função de coordenadores-gerais, coordenadores, chefias ou estejam lotados em equipes de recursos humanos". (Escola Nacional de Administração Pública, 2013, p. 45)

Os objetivos de aprendizagem do programa são os seguintes:

- reconhecer a importância e as contribuições da gestão por competências para o aprimoramento das práticas de gestão de pessoas na administração pública;

- entender a importância do mapeamento de competências para o diagnóstico preciso de necessidades de capacitação;

- elaborar planos de capacitação segundo as competências individuais identificadas e mapeadas;

- reconhecer a importância do trabalho em equipe no contexto das organizações;

- discutir as diretrizes de planos de carreira no âmbito do Poder Executivo federal à luz da gestão de pessoas por competências;

- identificar a Lei no 8.112/90 e legislação complementar como instrumentos de gestão de pessoas no âmbito da administração pública federal. (ENAP, 2013, p. 45, grifos nossos).

Dos seis objetivos de aprendizagem, quatro se referem diretamente às competências: importância e contribuições da gestão por competências; mapeamento de competências; elaboração de plano de capacitação segundo competências individuais; discutir diretrizes de planos de carreira à luz das competências. Um dos objetivos se refere indiretamente às competências: cita a lei e legislação complementar, que são, por sua vez, as que instituem a noção de competências na gestão pública. Isso demonstra a força desse enunciado na formação dos servidores.

Já o quarto item, em primeira análise, parece destoar dos demais: reconhecer a importância do trabalho em equipe no contexto das organizações. De fato, o enunciado das competências, que apresenta um foco nitidamente individual (o desenvolvimento do trabalhador), vem frequentemente acompanhado pelo discurso de desenvolvimento das competências das equipes e das organizações, conforme pode-se constatar nos documentos.

Segundo Faria e Leal (2007), o enunciado de trabalho em equipe responde diretamente ao discurso administrativo contemporâneo que supervaloriza o relacionamento entre os pares, de modo que os trabalhadores permanecem em constante relação dicotômica de cooperação e competição, trabalho individual e coletivo, dado que, apesar do incentivo ao trabalho em equipe, cooperação e participação coletiva, o trabalhador costuma ser avaliado em suas competências individuais.

A metodologia do programa da ENAP é composta por: exposições dialogadas, exercícios práticos, relato de experiências, estudos de casos, simulações, dinâmicas em grupo e leitura dirigida. As metodologias empregadas têm em comum um forte apelo prático, utilitarista e interacionista, ou seja, buscam a difusão de uma metodologia por meio de leituras, relatos e rápidas trocas de experiência. Assim, o curso funciona como uma ferramenta que fortalece os efeitos de sentido do enunciado das competências. Em sua pragmática comunicativa, esses efeitos são também produtivos em sua tensão constitutiva, uma vez que, enquanto produzem a dádiva da competência - ou do ser competente -, ameaçam pela incompetência.

A estrutura do programa é a seguinte, conforme Catálogo 2013 da ENAP (p. 45): "Os temas são interrelacionados, mas independentes. Os cursos podem ser selecionados pelo servidor, segundo o seu interesse, necessidade e disponibilidade de tempo". Essa estrutura está alinhada às necessidades da organização flexível: o servidor tem liberdade para escolher qual curso irá fazer, e em que momento. O programa de gestão de pessoas é composto por nove cursos independentes, 
com carga horária de cerca de vinte horas cada um, o que possibilita que o servidor frequente as aulas sem deixar de realizar as atividades - e entregas - de seu trabalho. Ou seja, trata-se de uma formação autônoma e flexível, direcionada para um trabalhador autodeterminado e autovigilante, e acessível a todos os servidores públicos.

Conforme preconizado pela teoria da competência desde sua criação, a oportunidade de educação e de inclusão se concretiza em forma de políticas de educação, de caráter formal e não formal, flexível, em um contexto global de grande competitividade e busca por resultados imediatos. Tornar-se competente tornou-se objeto de consumo do trabalhador.

A capacitação por competências, assim, tornou-se dominante e naturalizada nas políticas públicas e práticas educativas, não sendo problematizada em seus pressupostos e seus efeitos: o tipo de trabalhador - competente - que se almeja produzir. A seguir, propõe-se dessacralizar tal concepção, confrontando-a em seus pressupostos, construindo a arena de vozes, para se fazer ouvir outros posicionamentos.

\section{Educação por competências para (in) excluir: debates contemporâneos}

Nossa análise aponta a presença de um discurso internacional e nacionalmente legitimado pela teoria das competências, aliada à educação continuada, que preconiza a inclusão social, a igualdade de oportunidades e a redução de injustiças sociais. Seria então a política de capacitação nacional uma oportunidade dada aos servidores públicos para se capacitarem de modo contínuo e assim possibilitar a prestação de um serviço público de qualidade aos cidadãos do país?

Se por um lado os documentos públicos analisados legitimam o enunciado e reforçam a importância da capacitação por competências, por outro, existem autores que manifestam vozes dissonantes ao enunciado (dominante) das competências, e que o apontam justamente como produtor dos processos de exclusão, pois ao mesmo tempo em que se investe na competência, produz-se a instabilidade e precarização do trabalho (Ferreira, 2000; Ramos, 2011; Gentili, 2000; Palangana, 2002).

Ferreira (2000) assinala que a noção de competência, ao oportunizar a inclusão, enquanto projeto de direito civil, contribui para a manutenção de dualizações no mundo do trabalho: qualificação/desqualificação; emprego/desemprego; vinculação contratual estável/vínculos contratuais precários e inclusão social/exclusão social.

Do ponto de vista bakhtiniano, tais dualizações são parte do próprio enunciado, multivocal, situado na arena de vozes, sempre. Porém, encontra-se naturalizado como verdade universal, cuja dimensão silente revela-se em seus efeitos produtivos na subjetividade no trabalhador: a sedução e a ameaça por tornar-se competente, tornar-se competente em pouco tempo e de modo flexível e autônomo, em uma realidade social marcada pelo desemprego estrutural e por condições educacionais historicamente desfavoráveis às classes trabalhadoras.

Segundo Ramos (2011), a suposta empregabilidade que o desenvolvimento de competências garantiria não costuma ser confrontada com o desemprego estrutural e com a altíssima competitividade que as taxas de desemprego denunciam.

Em relação a essa temática, Gentili (2000) afirma que é crítico reduzir a educação à sua função de potencializar o acesso ao trabalho. No cenário atual, a educação de qualidade tem se tornado uma mercadoria, de modo que apenas algumas minorias têm acesso a ela. Segundo Gentili (2000, p. 249): "a educação para o emprego pregada pelos profetas neoliberais, quando aplicada ao conjunto das maiorias excluídas, não é outra coisa senão a educação para o desemprego e a marginalidade".

Também Van der Klink e Boon (2002) apontam que um conceito tão flexível como o das competências, ao ser aplicado em um mecanismo rígido de classificações, acreditações e 
recompensas, tende a ter graves consequências para os grupos marginalizados. Segundo Mészáros (2002), a manutenção da desigualdade do acesso à educação é necessária à manutenção da "desigualdade geral", de forma que a igualdade de oportunidades não passaria de uma construção ideológica, quando inserida em um contexto neoliberal.

Assim, autores de diversas matrizes axiológicas críticas apontam a educação por competências como aquela que oportuniza e, ao mesmo tempo, aquela que exclui, configurando o que Sawaia (2001) define como dialética inclusão/exclusão. A educação por competências, no seu molde de educação flexível e autônoma, oportuniza o acesso a um desenvolvimento que, porém, não rivaliza com a sociedade marcada pela exclusão e marginalização que diversos pesquisadores denunciam (Gentili, 2000; Van der Klink, \& Boon, 2002; Palangana, 2002; Mészáros, 2002; Ramos, 2011; Jeris et al., 2005).

A etimologia da palavra competências, inclusive, traz em sua dimensão semântica, o significado de competição e exclusão: provém do latim competère, que significa "competir, concorrer... atacar, hostilizar" (Faria \& Leal, 2007, p. 145).

Faria e Leal (2007, p. 165) afirmam que a gestão por competências: (1) configura um padrão de comportamento que "hierarquiza" os trabalhadores segundo o seu "talento"; (2) estabelece as condições de desempenho que serão capazes de mantê-los empregados; e (3) manipula sua psique. $O$ processo de gestão por competências pressupõe, de fato, um levantamento prévio das competências valorizadas na organização - um protótipo do trabalhador desejado - que é definido segundo o posicionamento ideológico dominante. Quem estabelece as competências prioritárias, e com base em que critérios? São essas questões que ainda não apresentam solução pacífica entre os pesquisadores da área.

Após definidas as competências, o trabalhador é tratado como objeto a ser catalogado e quantificado, segundo a apresentação mais ou menos explícita de determinadas características (Ramos, 2011). Pela visão meritocrática, se é ou não é capaz de conquistar emprego (seja público ou privado) e a vida que cada trabalhador leva depende (apenas) da sua força de vontade. Os melhores indivíduos, os mais preparados, têm maior valor no mercado.

O conceito de empregabilidade, muito utilizado na atualidade, é uma forma de catalogação (Faria, \& Leal, 2007; Ramos, 2011). É o que se assiste hoje nas instituições e organizações governadas pelo enunciado das competências (o qual, inclusive, já foi adotado em alguns editais de concursos públicos): os "melhores" são selecionados, livra-se dos "piores"; capacita-se aqueles em quem se vale a pena investir (e nas áreas consideradas estratégicas para a organização); e medemse os resultados da capacitação de acordo com os resultados apresentados pelo trabalhador para a instituição. Finalmente, o ciclo da seleção reinicia, quando a organização (re)avalia o interesse em manter ou descartar o sujeito em questão. De fato, a gestão por competências hierarquiza e cataloga os trabalhadores segundo o seu suposto talento (Faria, \& Leal, 2007), criando um senso de valor/competência (provisório) para uns e gerando sentidos de incompetência para os demais trabalhadores.

No caso de servidores estáveis da administração pública brasileira, diversas carreiras já atrelam a progressão do servidor à avaliação de desempenho. Dessas, muitas são realizadas por critérios de competência. Ou seja, nessas avaliações, os identificados como melhores ou piores são catalogados e recebem remuneração distinta. Assim, verifica-se que o desenvolvimento de competências na área pública trabalha no sentido de legitimar a competência do trabalhador, muitas vezes configurado como burocrata folgado, aquele não trabalha, sendo remunerado sem a adequada prestação de serviços.

Em suma: a educação continuada por competências nem sempre promove a igualdade de oportunidades e os processos de inclusão preconizados pelas políticas. O que se verifica é que, a partir da legitimação da teoria, a responsabilização sobre a situação em que se encontra recai quase 
que exclusivamente sobre o indivíduo. No serviço público, a competência do Estado é transferida para a competência individual do trabalhador.

\section{Ser trabalhador público: entre a competência e a incompetência, a justiça e a saia justa}

Com as recentes transformações no mundo do trabalho, o conhecimento passa a ser cada vez mais provisório, o que exige que o trabalhador busque a constante atualização de seus conhecimentos e competências (Ramos, 2011). Assim, todos os tempos - o dia, a noite, a madrugada - e espaços - a casa, a escola, o trabalho - são considerados como próprios para a aprendizagem, e colocam o trabalhador a se qualificar incessantemente, de modo autônomo, para competir no mercado das competências/dos competentes. $\mathrm{O}$ sentido que se estabelece é que o consumo compulsivo da educação asseguraria a competência do trabalhador (Rodrigues, 2008).

O enunciado das competências, ao adentrar as políticas públicas de educação do servidor, apresentando-se de modo hegemônico, monológico e naturalizado, ou seja, assumindo um caráter de verdade universal, convoca rapidamente o trabalhador à sua adesão.

À satisfação de que interesses o servidor público brasileiro tem servido, então, em sua busca incessante pela autocapacitação? É crescente o entendimento de que "os trabalhadores devem ser considerados como um custo e uma variável de ajuste do sistema, adaptáveis, flexíveis, renováveis, entre outras propriedades, com vistas a corresponder às exigências de mercado" (Chiavegato Filho, \& Navarro, 2012, p. 68). Enquanto se investe e evidencia-se o desenvolvimento de competências do servidor, silenciam-se os questionamentos referentes às suas condições de trabalho e gestão pública.

Em relação ao serviço público, Amaral (2006, p. 559) afirma que o desafio está em "conseguir oferecer formas de aprendizado voltadas para reflexão, criatividade e iniciativa de modo a contribuir para a preparação de servidores capazes de agir, tomar decisões e melhorar a gestão pública no país". Nesse enunciado percebe-se o sentido fortemente difundido de que a melhoria da gestão pública no país depende essencialmente do desenvolvimento das competências dos servidores.

O servidor é responsabilizado pela possível melhoria dos serviços públicos, por meio do desenvolvimento de suas próprias competências - e, inversamente, pelos serviços públicos de baixa qualidade ofertados ao cidadão. Justiça ou saia justa?

De acordo com Alves (2006, p. 51), "o atual regime capitalista, produtor de um discurso econômico que se sobrepõe a todos os outros e que é estruturante do discurso oficial, utiliza a Ciência e as instituições do Estado para controle do indivíduo e de seu corpo". De fato, no âmbito da administração pública, o sentido da incompetência do servidor configurado pelas políticas públicas de educação pode responder a interesses de minimização dos espaços estatais, justificando possíveis privatizações ou terceirização de serviços considerados essenciais, conforme preconiza o pensamento neoliberal. A representação do servidor público é desmantelada; ele é marcado sob o signo da incompetência. Suas condições de trabalho são precarizadas no capitalismo atual ao ponto em que a incompetência (ou desinteresse na) da gestão dos espaços e serviços públicos é percebida como a incompetência dos próprios servidores.

Diante da lógica competitiva de "crueldade e selvageria" atuante na esfera do trabalho, em que os pares funcionam como mecanismos de controle um dos outros (Faria, \& Leal, 2007, p. 153), resta a confiança no autodesenvolvimento, com foco superindividual, para se diferenciar dos colegas de trabalho, estes percebidos como concorrentes. Nessa guerra pela autocapacitação, portanto, nenhum tipo de coletividade sobrevive; nenhum sentimento de pertencimento, seja a cargo, instituição ou carreira, mantém-se. Sem o outro, a única ética possível é a da indiferença (Sennett, 1999).

Ainda em relação à ética, resta a questão da legitimidade de um sujeito para a aferição das competências dos trabalhadores. Quem são os sujeitos suficientemente capacitados para realizar 
a medição de competências a partir de critérios ditos objetivos, sendo que o comportamento dos trabalhadores são alterados em função das situações em que se encontram, situação essa que é também produzida pelo próprio avaliador? E como medir competências, diante de uma profusão tão grande de conceitos e usos do termo (Van der Klink, \& Boon, 2002)? A aferição das competências parece ser um problema crítico que não tem sido suficientemente trabalhado pelos defensores da teoria.

Nas atuais práticas educativas pautadas pelo enunciado das competências, não há distanciamento entre o sujeito e o discurso que o produz. Essa relação de poder desponta ao se analisar as políticas de educação, nas quais o trabalhador é posto como objeto, destituído de posicionamento crítico, pois é ele o próprio produto, a entrega, da educação flexível; torna-se objeto e produto de consumo. Configura-se um sujeito com um perfil (conjunto de competências) específico: polivalente, flexível, que atua no seu limite (e inclusive adoece se for preciso), mas incapaz de questionar as políticas públicas e as práticas educativas e de trabalho.

O enunciado das competências, portanto, produz modos de subjetivação que conferem aos sujeitos lugares sociais específicos, cujos efeitos de sentido não se restringem à dimensão técnica do trabalho, mas se propagam para sua vida e relações cotidianas. $\mathrm{O}$ enunciado produz, assim, modos específicos de ser humano, nos quais ser competente torna-se questão central na vida do trabalhador (Sennett, 1999).

Osentido do enunciado das competências compõe-se dialeticamente com o da incompetência, formando uma mesma unidade de sentido. $\mathrm{O}$ enunciado multivocal produz fortes sentidos de ameaça ao trabalhador - que é um potencial desqualificado, desempregado ou nominado burocrata folgado - e, na concepção dos autores críticos citados, são decorrentes de um modo de produção capitalista que divide, seleciona, aparta, discrimina. $\mathrm{O}$ trabalhador, portanto, submete-se aos incessantes processos de capacitação, em toda hora e local, com a profunda confiança de que, assim, tornar-se-á competente, e será salvo da ameaçadora e vergonhosa incompetência.

As teorias das competências conseguem armar o todo discursivo de modo a reunir em uma só matriz semântico-axiológica os mais diversos sentidos, tornando-se uma maquinaria simbólica poderosa na produção de conhecimentos para educar e formar, e, mais além, para a configuração da subjetividade do trabalhador: competente, flexível, autovigilante, competitivo, autônomo, responsável e comprometido com o resultado da produção e dos serviços prestados, pouco crítico e reflexivo.

\section{Conclusões}

Diante dos serviços públicos de baixa qualidade ofertados aos cidadãos e da precarização das condições de trabalho (Costa, 2005; Andrade, 2011; Chiavegato Filho, \& Navarro, 2012), estaria a (in)competência de gestão pública brasileira sendo habilmente transferida à figura individual do servidor, quando se anuncia a necessidade de profissionalização do setor público, por meio da capacitação de seus servidores? Esse é um sentido que pode ser apreendido a partir da leitura da política de capacitação nacional. Se há que se investir com urgência na profissionalização e no desenvolvimento de competências do servidor, abre-se campo para supor sua falta de profissionalismo e (in) competência.

As políticas de capacitação (re)produzem efeitos de sentido sobre as representações dos servidores públicos que estão inseridos nas ações de educação continuada do governo federal brasileiro. $\mathrm{O}$ enunciado das competências, como forma de oportunizar qualificação, inclusão e sucesso, de modo rápido e flexível, revelou-se como um potente e competente aliado do Estado capitalista, ao dirigirse diretamente ao Ser do trabalhador, ao seu modo de existir e posicionar-se no mundo, produzindo um trabalhador que se responsabiliza individualmente por suas competências e capacidade de entrega. 
Assim, embora os fundamentos do termo competências estejam silenciados na literatura, seus usos e efeitos podem ser lidos em sua perspectiva pragmática, produzindo um trabalhador autônomo e flexível.

Quais, afinal, os limites do enunciado das competências? O desenvolvimento das competências individuais dos servidores é suficiente para a efetiva melhora dos serviços públicos, ou há outros fatores - silenciados - que precisam ser problematizados? Em outras palavras: seria a formação (e responsabilização) individual a saída para a efetiva qualificação do serviço público?

O presente trabalho abre espaço para que novas pesquisas possam aprofundar na análise das relações de poder existentes na arena, por meio da investigação de como a política pública de educação pautada em competências tende a produzir um modo de leitura do trabalhador sobre quem ele é e pode vir a ser (posso tornar-me competente!) que seduz pelo monologismo e enfraquece questionamentos sobre o que vem a ser, afinal, um trabalhador competente.

A pesquisa, ao refletir sobre o discurso das competências, suas contradições, seus marcos históricos e legais, e possíveis configurações subjetivas do servidor, abre campo para investigações empíricas sobre a forma como os servidores têm respondido e se posicionado frente ao enunciado: há adesão e recusa, há resistência ativa e passiva, há adoecimento? Ou o trabalhador público está identificado e alinhado aos moldes da educação e do consumo, consumindo avidamente educação para tornar-se competente? Ao adotar a política incondicionalmente, consumi-la crua, submeterse a ela, o servidor público atua como próprio objeto-produto.

Conhecer os efeitos das complexas práticas de capacitação pautadas em competências no cotidiano dos trabalhadores públicos e como o servidor tem se posicionado eticamente diante de inúmeras demandas subjetivas e objetivas preconizadas pela educação continuada, esta diretamente alinhada à entrega de resultados, é o desafio que se apresenta. Perante as intensas modificações no mundo do trabalho, a adoção de um modelo que não teorize as relações de poder como parte da construção do conhecimento é problemática. O caráter político da educação pode ser lido por meio das próprias práticas públicas e sua normatização, posicionadas na arena de vozes - nunca apolíticas ou neutras (Machado, \& Pan, 2014).

Se, por um lado, o enunciado das competências produz grande dissonância conceitual, o próprio enunciado responde de forma monologizada (hegemônica) a interesses convergentes. O discurso das competências opera de modo mais eficaz sobre a produção da subjetividade do trabalhador, incluindo a todos, oferecendo oportunidade a todos, no plano da teoria. A educação liberal e flexível, por sua vez, responde diretamente às necessidades do capital, acirrando desigualdades sociais e ampliando os processos de exclusão das minorias.

O estudo proposto demonstra a importância da análise discursiva dos documentos que preconizam as políticas públicas de educação, pois tais documentos produzem sentidos de verdade para o trabalhador que, se não forem desnaturalizados, situados, contextualizados historicamente e problematizados, assumem sentido de verdade universal, dificultando a compreensão de suas relações e consequentemente o questionamento e o posicionamento crítico do trabalhador.

A melhoria do serviço público limita-se ao desenvolvimento de competências do servidor ou engloba posicionamentos éticos, políticos, a priorização de interesses econômicos e sociais - esses silenciados, enquanto se discute a política pública de capacitação? $\mathrm{O}$ assunto merece a atenção dos pesquisadores em ciências humanas.

\section{Referências}

Alves, L. A. (2006). Referências para a formação de professores: uma análise crítica sobre o discurso da qualidade e competência, do ponto de vista da Psicologia Escolar (pp. 47-76). In L. S. Viégas, \& C. B. Angelucci (Orgs.), Políticas públicas em educação $\mathfrak{E}$ psicologia escolar. São Paulo: Casa do Psicólogo. 
As políticas de educação continuada por competências: um estudo das configurações subjetivas do trabalhador público brasileiro

Andrade, D. P. (2011). Empresa humana ou humana empresa? Revista de Administração Pública, 10 (1), 38-41.

Amaral, H. K. (2006). Desenvolvimento de competências de servidores na administração pública brasileira. Revista do Serviço Público, 57 (4), 549-563.

Amorim, M. (2002). Vozes e silêncio no texto de pesquisa em Ciências Humanas. Cadernos de Pesquisa, 116, p. 7-19.

Bakhtin, M. (2011). Estética da criação verbal. São Paulo: Martins Fontes.

Boterf, G. L. (1997). Construire la compétence collective de l'entreprise. Gestion, 22 (3), 82-85.

Chiavegato Filho, L. G., \& Navarro, V. L. (2012). A organização do trabalho em saúde em um contexto de precarização e do avanço da ideologia gerencialista. Revista Pegada, 13 (2), 67-82.

Costa, M. S. (2005). O sistema de relações de trabalho no Brasil: alguns traços históricos e sua precarização atual. Revista Brasileira de Ciências Sociais, 20 (59), 111-131.

Decreto $\mathrm{n}^{\mathrm{o}}$ 5.707, de 23 de fevereiro de 2006. (2006, 23 de fevereiro). Institui a política e as diretrizes para o desenvolvimento de pessoal da administração pública federal direta, autárquica e fundacional, e regulamenta dispositivos da Lei no 8.112, de 11 de dezembro de 1990. Diário Oficial da União, Brasília. Recuperado de https:// www.planalto.gov.br/ccivil_03/_Ato2004-2006/2006/Decreto/D5707.htm [09 dezembro 2016]

Delors, J. (Org.). (2003). Educação, um tesouro a descobrir: relatório para a UNESCO da Comissão Internacional sobre a educação para o século XXI (8aㅡ ed.). São Paulo/Brasília: Cortez/MEC/UNESCO.

Dutra, J. S., Fleury, M. T. L., \& Ruas, R. L. (Orgs.) (2012). Competências: conceitos, métodos e experiências. São Paulo: Atlas.

Escola Nacional de Administração Pública (2013). Catálogo de cursos 2013. Recuperado de http://repositorio.enap.gov. br/bitstream/handle/1/796/Catálogo\%20de\%20Cursos\%202013.pdf?sequence=1\&isAllowed=y [14 dezembro 2016]

Faraco, C. A. (2003). Linguagem e diálogo: as ideias linguísticas do círculo de Bakhtin. Curitiba: Criar Edições.

Faria, J. H., \& Leal, A. P. (2007). Do treinamento à universidade corporativa: ideologia, dominação e controle. In J. H. Faria (Org.), Análise crítica das teorias e práticas organizacionais. São Paulo: Atlas.

Fleury, M. T. L., \& Fleury, A. (2001). Construindo o conceito de competência. Revista de Administração Contemporânea, 5 (ed. esp.), 183-196.

Flick, U. (2009). Introdução à pesquisa qualitativa. Porto Alegre: Artmed.

Gentili, P. (Org.) (2000). Pedagogia da exclusão: o neoliberalismo e a crise da escola pública. Petrópolis, RJ: Vozes.

Jeris, L., Johnson, K., Isopahkala, U., Winterton, J., \& Anthony, K. (2005). The politics of competence: views from around the globe. Human Resource Development International, 8 (3), 379-384.

Machado, J. P., \& Pan, M. A. G. S. (2012). Do nada ao tudo: políticas públicas e a educação especial brasileira. Educação E Realidade, 37 (1), 273-294.

Machado, J. P., \& Pan, M. A. G. S. (2014). Política pública e subjetividade: a assistência estudantil na universidade. Textos $\mathbb{E}$ Contextos, 13 (1), 184-198.

McClelland, D. (1973). Testing for competence rather than for "intelligence". American Psychologist, 28 (1), 1-14.

Mészáros, I. (2002). Para além do capital: rumo a uma teoria da transição. São Paulo: Boitempo.

Palangana, I. C. (2002). Individualidade: afirmação e negação na sociedade capitalista. São Paulo: Summus.

Pereira, L. D. (2006). A reação burguesa à crise capitalista e o processo de mercantilização do ensino superior no pós1970. Textos \& Contextos, 5 (1), 1-21.

Perrenoud, P. (1998) Construire des compétences, est-ce tourner le dos aux savoirs? Résonances: Mensuel de L'École Valaisanne [Dossier Savoirs et compétences], 3, 3-7.

Ramos, M. N. (2011). A pedagogia das competências: autonomia ou adaptação? São Paulo: Cortez.

Rodrigues, M. M. (2008). Educação ao longo da vida: a eterna obsolescência humana. Tese de doutorado, Programa de PósGraduação em Educação da Universidade Federal de Santa Catarina, Florianópolis.

Sawaia, B. (Org.) (2001). As artimanhas da exclusão: análise psicossocial e ética da desigualdade social (3ª ed.). Petrópolis: Vozes.

Sennett, R. (1999). A corrosão do caráter: as consequências pessoais do trabalho no novo capitalismo. Rio de Janeiro: Record. Silva, T. T. da (1998). Liberdades reguladas: a pedagogia construtivista e outras formas de governo do eu. Petrópolis: Vozes. 
Spink, M. J. (1999). Análise de documentos de domínio público. In Práticas discursivas e produção de sentidos no cotidiano: aproximações teóricas e metodológicas (pp. 123-152). São Paulo: Cortez.

Sposito, M. P. (2008). Trajetórias na constituição de políticas públicas de juventude no Brasil. In M. V. de Freitas, \& F. C. Papa (Orgs.), Políticas públicas, juventude em pauta (pp. 57-74). São Paulo: Cortez/Ação Educativa.

Van Der Klink, M., \& Boon, J. (2002). Competencies: the triumph of a fuzzy concept. Proceedings of the Academy of Human Resource Development Annual Conference, Honolulu, 1, 327-334.

Zarifian, P. (2001). Objetivo competência: por uma nova lógica. São Paulo: Atlas.

\section{Endereço para correspondência}

luanasilvy@hotmail.com, miriamagspan@yahoo.com.br
Recebido em: 30/07/2015

Aprovado em: 30/11/2016 